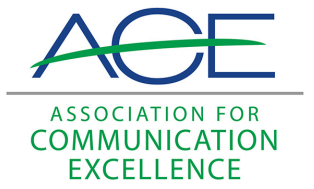

Journal of Applied Communications

\title{
Creating Relevancy in Agricultural Science Information: Examining the Impact of Motivational Salience, Involvement and Pre-Existing Attitudes on Visual Attention to Scientific Information
}

\author{
Laura Morgan Fischer \\ University of Kentucky \\ Courtney Meyers \\ Texas Tech University \\ R. Glenn Cummins \\ Texas Tech University
}

See next page for additional authors

Follow this and additional works at: https://newprairiepress.org/jac

Part of the Agricultural and Resource Economics Commons, and the Public Relations and Advertising Commons

(c) (i) (2)

This work is licensed under a Creative Commons Attribution-Noncommercial-Share Alike 4.0

License.

\section{Recommended Citation}

Fischer, Laura Morgan; Meyers, Courtney; Cummins, R. Glenn; Gibson, Courtney; and Baker, Mathew (2020) "Creating Relevancy in Agricultural Science Information: Examining the Impact of Motivational Salience, Involvement and Pre-Existing Attitudes on Visual Attention to Scientific Information," Journal of Applied Communications: Vol. 104: Iss. 2. https://doi.org/10.4148/1051-0834.2287

This Research is brought to you for free and open access by New Prairie Press. It has been accepted for inclusion in Journal of Applied Communications by an authorized administrator of New Prairie Press. For more information, please contact cads@k-state.edu. 


\title{
Creating Relevancy in Agricultural Science Information: Examining the Impact of Motivational Salience, Involvement and Pre-Existing Attitudes on Visual Attention to Scientific Information
}

\author{
Abstract \\ Agricultural communications literature has indicated scientists are struggling to make information salient \\ to consumers. Prior studies have examined the efficacy of message frames and types of appeals that \\ increase visual attention and information processing among general consumers. Research suggests that \\ value-oriented frames may connect with consumers through increased personal involvement and \\ motivational salience. To evaluate the effects of competing message frames on visual attention, an eye- \\ tracking experiment was conducted to understand the interaction between pre-existing attitudes and \\ issue involvement on participants' attention to messages about genetic modification and antibiotic use in \\ livestock. For products that are low in issue involvement (i.e., food products and scientific information), \\ the results indicated the reader devoted more time to reading advertisements that were framed to be \\ more motivationally salient (i.e., the value-oriented frame). Because selective attention is the first part in \\ the sequence of how individuals process information and form attitudes, agricultural science \\ communicators should highlight values and motivational salience in their messaging. Recommendations \\ for practitioners and the use of eye tracking as a research tool are described.

\section{Keywords} \\ Advertorials, Motivation, Salience, Value-Oriented, Visual Attention Allocation \\ Cover Page Footnote/Acknowledgements \\ This manuscript was presented at the 2018 Association for Education in Journalism and Mass \\ Communication (AEJMC) in Washington, DC. This material is based upon work that is supported by the \\ NLGCA Capacity Building Grants [grant no. 2017-70001-25991] from the USDA National Institute of Food \\ and Agriculture.

\section{Authors} \\ Laura Morgan Fischer, Courtney Meyers, R. Glenn Cummins, Courtney Gibson, and Mathew Baker
}




\section{Introduction}

Although science has changed life for the better, and many members of the public have a positive attitude toward science, there is still polarization between the opinions and views of scientists, scientific organizations, and the general public. In particular, U.S. citizens and scientists have often differed on their opinions of science-related topics and issues (Funk \& Rainie, 2015; Pechar, Bernauer, \& Mayer, 2018). In addition to lack of agreement, trust in the sciences has become an issue for the scientific community - both with scientific corporations and scientists regarding several topics including climate change, genetically modified (GM) food, and pesticide use in food production. Previous research has also indicated this trend is continuing with food production and agricultural production practices, with increasing levels skepticism and enhanced polarization (Rumble \& Irani, 2016; Weatherell, Tregear, \& Allinson, 2003). In fact, industry stakeholders and researchers alike have implied consumers do not accept what scientists and scientific organizations say to be true (Pechar et al., 2018). Industry reports have continually tracked decreased trust and more negative attitudes toward information about where food comes from and the sources that distribute the information (Center for Food Integrity, 2014; Funk \& Rainie, 2015; Rummo, 2016). Likewise, other agricultural science organizations have reported trust with consumers as a major issue within the agricultural industry. The vice president of Bayer Crop Sciences, David Hollinrake, was quoted on the topic of decreasing trust: “There are many challenges facing today's food producer and perhaps none more important than trust with consumers" (Bayer Corporation, 2016, para. 2).

Movement away from the farm and minimal scientific education throughout K-12 programs has led many to disconnect, distrust, and even be afraid of companies, people, and entities regarding scientific systems (Duncan \& Broyles, 2006). Hartz and Chappell (1997) claimed the lack of trust of scientists, including agricultural scientists, from the public has threatened the political and economic aspects of science and science communications particularly in regard to policy and market debates. Scott, Inbar, and Rozin (2016) documented evidence of absolute moral opposition to genetically modified food despite their potential benefits. As an example, fear toward genetically modified organisms (GMOs) and its potential health concerns have led to labeling bills and laws (Blake, 2016). Although agricultural practices such as antibiotic use in livestock and genetic modification have been used to increase efficiency in agricultural production, these same production procedures have led to consumers asking critical questions relating to personal health and the environment (Roberts et al., 2016). Popular press articles have continued to fuel these misperceptions, and it has also provided an opportunity for many companies to jump on the antibiotic-free, pesticide-free, and GMO-free "bandwagon" (Rummo, 2016, para. 2), and market products with many labels that are often unnecessary. Companies may capitalize on these interests by creating labels appealing to the consumer's preferences for antibiotic-free, pesticide free, and GMO-free foods. However, marketing toward these preferences promotes the perception of risk and further drives skepticism of these agricultural production practices (Rummo, 2016). Because public opinion shapes many policy, legislative, and market decisions, increasing trust and knowledge within the sciences is crucial for increased scientific innovation and production efficiency (Conway \& Waage, 2010).

Although lack of trust in the scientific food industry impacts policy and market decisions, the disconnect from agricultural entities has also fed into cultural movements such as foodrelated education programs, foodie movements, community-supported agricultural programs, and food marketing tactics (Roberts, Harder, \& Brashears, 2016). These cultural movements have shown the public has an increased interest about food production and systems, and this interest 
has led to more "questions about the merits of different agricultural production systems" (Roberts et al., 2016, p. 14).

Agricultural scientists have relied on the media and communicators to disseminate scientific and health-related information (Ruth, Lundy, Telg, \& Irani, 2005). Communication of scientific information is dependent upon "the actors that play a role in communicating science via the media (whether that be scientists, journalists, government and non-governmental organizations, public relations experts and the potential hotchpotch of individuals that comprise the blogger community)" (Weitkamp, 2016, p. 1). To build trust with consumers, organizations within the agricultural sciences have traditionally sought to provide logical or scientific reasoning to communicate about these issues with the private sector and consumers (Rumble \& Irani, 2016; Woteki, 2012). However, when using this logical or scientific reasoning approach, these same agricultural organizations struggle to capture attention and communicate with a variety of audiences, which may be one of the reasons that industry stakeholders are reporting the knowledge and trust gap between consumers and scientists is continuing to grow (Ruth, Gay, Rumble, \& Rodriguez, 2015).

To communicate about the sciences effectively, one important element may be to understand the "forces that affect how people encountered, interpret, and use scientific information in these circumstances" (National Academies of Sciences, Engineering, and Medicine, 2017, p. 52). Scholars and practitioners alike have suggested that information about the sciences must be structured in a way that is motivationally relevant and salient to their publics (Bucchi, 1998; Pechar et al., 2018; Scheufele, 2013). Specifically, before attitudes can be changed, communicators must gain the attention of viewers. One means of doing this is to employ message frames that resonate with audiences in the form of a visual message. Thus, the goal of this experiment was to understand how competing message frames impacted attention directed toward messages on scientific issues as a function of individual involvement and preexisting attitudes.

\section{Message Frames}

\section{Literature Review}

One way of achieving this increased relevance is through framing of messages. Message frames are crucial to improving strategic communication (i.e., crafting messages toward a specific, targeted audience) and are an effective way to communicate about social science issues (Fischer et al., 2018; Warner, Rumble, Martin, Lamm, \& Cantrell, 2015). The selection of targeted message frames allows communicators to make information salient to a specific audience while encouraging particular behaviors, evaluations, or attitudes (Entman, 1993). A frame of reference may be set when a reader, viewer, or listener interprets specific information in a message based on how the source presents the information (Scheufele, 1999).

Studies have indicated tailored message frames are necessary when achieving strategic communication goals (i.e., Dixon, Hmielowski, \& Ma, 2017). Previous research has discussed how communication materials impacts a consumer's previously held perception of the agricultural industry, either positively or negatively (Abrams \& Meyers, 2012; Goodwin, Chiarelli, \& Irani, 2011; Ruth, Lundy \& Park, 2005). The message frame refers to highlighted aspects of the communication or message that are selected to affect affective, cognitive, and behavioral processes (Shen \& Bigsby, 2013). In particular, when used in persuasive messaging, frames provide a way to help the receiver to think about the information more careful and to find the information as truthful (Petty \& Cacioppo, 1986; Shen \& Bigsby, 2013). 
Message frames have been researched in a variety of ways in the agricultural industry. Previous researchers have found message frames must contain information that satisfies the consumers' need for content while also appealing to the motivations, social and personal beliefs of the receiver (Abrams \& Meyers, 2012; Gorham, Rumble, \& Holt, 2015; Goodwin et al., 2011). Communicators may appeal to consumer motivations by emphasizing these social benefits of a particular issue, such as purchasing local food, or appealing to a consumer's emotion by adding empathy to make a voter support specific legislation (Gorham et al., 2015; Goodwin et al., 2011).

When communicating with high-involvement audiences about agricultural science issues, a scientific reasoning frame may be the most appropriate, as participants with increased involvement have an interest in gaining a deeper understanding of the material (Fischer et al., 2018). Rather than focusing on logic-based arguments with consumers, communicators have been developing messages to appeal to the values, beliefs, motivations and/or emotions of the audience to make scientific information more motivationally salient to non-scientific audiences, such as food consumers (i.e., Brader, 2006; Lee, Scheufele, \& Lewenstein, 2005; Pecher et al., 2018). Value-oriented messaging may provide an opportunity to gain the attention of the target audiences as it allows the communicator to tailor and orient the information to the existing values of the target audience through a story or narrative, increasing their motivation to view the message (Shen \& Edwards, 2005; Warner et al., 2015). Value-oriented frames are prevalent in issue-based messaging and have been researched to understand how citizens respond to a particular issue (Brewer \& Gross, 2005). These frames are successful because they produce higher levels of information processing by activating "thoughts in memory participants would not otherwise recall; likewise, it may lead them to weigh thoughts to which they would otherwise attach little importance" (Brewer \& Gross, 2005, p. 935).

In particular, researchers have suggested information about scientific information tends to be a polarized subject, and the orientation of a message to an audience's personal values may warrant increased attention (Corner, Witmarsh, \& Zenias, 2012; Dodds, Tseëlon, \& Weitkamp, 2008; Shen \& Edwards, 2005; Warner et al., 2015) because the consumer tends to be more openminded, and even motivated about a topic when it is presented in a manner oriented with the values of the target audience (National Academies of Sciences, Engineering, and Medicine, 2017). Specifically, Shen and Edwards (2005) stated value frames associate a basic human value of the audience with an issue and a product (e.g., support gay marriage, buy this product). Researchers have also suggested aligning a message frame to a personal value leads to higher levels of information processing, issue relevant thoughts, attention, and more positive attitudes (Shen \& Edwards, 2005; Warner et al., 2015). Although researchers have suggested increased attention may be warranted due to more systematic processing, researchers in agricultural communications have not yet identified if specific message frames elicit increased visual attention.

\section{Selective Attention}

Behavior, whether it is to view a message or to act upon a situation, is goal-oriented, and people have developed inherent decision-making processes to act upon a behavior (Klink, Jengtens, \& Lorteije, 2014). This inherent decision-making process in visual attention allocation can be described as selective attention, or the viewer's allocation of attention to select specific elements in the visual field to process in greater depth. Within the literature, message-level and individual-level factors have influenced a viewers' selective attention to advertisements. 
Specifically, an individual's motivation to process information impacts the capacity that individual subsequently has to process information, resulting in selective attention to specific elements in the stimuli (Abrahamse, Majerus, Fias, \& van Dijck, 2017). The individual will selectively attend to information that is consistent with his or her prior beliefs, and will ignore information inconsistent with viewing goals, attitudes, or behaviors (Folk, Remington, \& Johnston, 1992; Smith, Fabrigar, Powell, \& Estrada, 2007). Furthermore, elements of an advertisement that are personally relevant (i.e., motivationally salient) to the individual have also increased attention (Klink et al., 2014; MacInnis \& Jaworski, 1989). For example, in MacInnis and Jaworksi's (1989) results about the processing of brand specific information, individuals were found to express longer durations of attention allocation to elements of the message that were consistent with their motivations and issue involvement. Further, duration to stimuli is documented to be longer with messages aligning with a viewing goal or value (Klink et al., 2014).

\section{Elaboration Likelihood Model}

This notion of selective attention can be aligned within the Elaboration Likelihood Model (ELM) as overt evidence of more in-depth processing. The ELM provides a model to explain how personal attributes and message attributes allow individuals to select and attend to particular aspects of persuasive information and whether these individuals process information through a systematic evaluation and analysis (i.e., the central route) or use heuristic cues to accept or reject the information (i.e., the peripheral route) (Petty \& Cacioppo, 1986). Elaboration likelihood has been used as a theoretical construct for attitude research regarding agricultural and natural resources topics. The Elaboration Likelihood Model was documented in Verbeke's (2005) literature review, which described how information processing was a major component affecting consumer's purchasing decisions. Further, this literature review cited ELM as a framework to guide this process. Verbeke and Ward (2006) used ELM to guide attitude formation of a beef traceability campaign in Belgium and the effect of information cues on the likelihood to elaborate.

Additionally, message testing and the evaluation of elaboration on message frames has been described by multiple researchers. Meyers (2008) used the framework to identify how persuasive communication influences media coverage of agricultural biotechnology. Her research found previously existing attitudes had more of an effect on attitudes toward agricultural biotechnology than issue involvement. Rumble and Irani (2016) used ELM to explore personal relevance and transparency on college students' perception and trust about the livestock industry. This study discovered transparency had an effect on attitude and trust; however, personal relevancy in the form of proximal geography was not impactful. Additionally, Ruth (2015) found when knowledge is low, individuals will use the peripheral pathway to assess a message regarding genetic modification (such as source credibility). Further, low source credibility (i.e., where someone does not perceive a source as trustworthy) will lead to smaller changes in attitude compared to a source with high source credibility.

Personal attributes such as issue involvement have been found to increase the central route processing of a message (Petty \& Cacioppo, 1986). From a selective attention perspective, this central route processing may be evidenced via increased visual attention. Increased amounts of visual attention indicate more cognitive resources are being allocated to the message (Duchowski, 2007). An individual who has a higher level of issue involvement will place more cognitive resources on the message as motivation to processes the information therein is 
increased (Celsi \& Olson, 1988). Central to the current study, issue involvement plays a critical role in the degree to which an individual processes information. Petty and Cacioppo (1979) operationalized issue involvement as the following:

High issue involvement occurs when an issue has intrinsic importance, or personal meaning, when people expect the issue to have significant consequences for their own lives, and when concerns about the immediate situational rewards are dwarfed by outcomes connected with the topic itself. (p. 1916).

Based on this definition, systematic processing will most likely occur when issue involvement is high, and individuals will have resistance to persuasive messages when they have low issue involvement to the message (Petty \& Cacioppo, 1979). The model also suggests more active central processing occurs "when an individual possess the motivation (e.g., personal relevance) and ability (e.g., knowledge) to processed the information and uses careful consideration, along with past experiences, to develop opinions" (Ruth \& Rumble, 2017, p. 73). Further, King and Baker's (2018) study suggested systematic, central processing may occur with higher issue involvement individuals as people "draw from memories to find relevant information" (p. 5) to create a behavior toward a stimulus. Therefore, if the communicator can align issue involvement with a message, then greater attention may be directed toward the message, yielding higher levels of processing, and greater likelihood of impacting attitudes and beliefs. For example, Borgida and Howard-Pitney (1983) found pre-existing condition variables such as personal involvement increases the receiver's perceived saliency of a message. Their research also found personal involvement increased systematic message processing. When perceived personal relevance was high, the message elicited a controlled response to the information, which is a direct correlation to increased attention. These results provide evidence that the relevance of the information to the receivers may activate a mechanism to stimulate the processing of the message (MacInnis \& Jaworkski, 1989).

Additionally, when consumers have low involvement with an advertisement, they may only "process the visual salient information and shift their attention away without attending to other less salient ad elements" (Gong \& Cummins, 2016, p. 9). This idea is further explained by prior literature suggesting that the majority of people are not motivated or highly involved with agriculture (Abrams \& Meyers, 2012), and when presented with information incongruent with their beliefs or values, individuals may process the "persuasive communication peripherally due to minimal motivation and ability” (Rumble, Rogers-Randolph, \& Buck, 2019, p. 8). Thus, visually salient information should be used to initially capture attention toward messages; however, messages with motivationally relevant information will generate more sustained visual attention allocation. Similarly, perceived personal relevance, or when an individual perceives the message to be self-related (i.e., the message is related to personal motives, goals, or values of the audience), the individual associates the message or product to be congruent with their personal goals, which has been known to drive consumer behavior (i.e., information processing, attitude formation, and visual attention; Guido, 2001).

\section{Visual Attention Allocation}

In simple terms, the construct of attention broadly refers to allocating cognitive and mental resources to a specific object or situation. Visual attention more specifically refers to eye movements to spatial locations, which has been connected to cognitive resources allocated to an 
area of a message (Duchowski, 2007). As noted in the ELM and other information processing theories and the concept of selective attention, humans cannot attend to all things at once. A hierarchy of effects occurs between how an individual allocates mental resources to stimuli, learns and remembers its content, and then develops an attitude. Because of these effects, visual attention allocation plays a role in information processing (Thorson, Chi, \& Leavitt, 1992). An individual's attention is used to focus mental resources on one specific object so the mind can process the stimulus of interest (Duchowski, 2007; Wu, 2011). To cope with the overwhelming volume of mediated information individuals encounter each day, viewers will choose to attend to specific messages and elements within a visual message, consequently adding bias to the media's effects (e.g., Zillman \& Bryant, 1985). Specifically, "if people are biased in their selection of information, it is almost certain that they must be biased in what they can remember because people obviously cannot remember information to which they are never exposed" (Smith et al., 2007 , p. 949). Essentially, the measurement of visual attention to media allows researchers to understand a "more granular assessment of not only attention to media message or platform over other elements in the environment, but also intra-stimulus selective attention to elements within a message" (Cummins, 2017, p. 1). Specifically, by tracking overt visual attention, researchers can uncover patterns of visual searches and time spent in specific areas on a stimulus and what attributes of the message the individual selects to allocate attention or cognitive resources (Abrahamse et al., 2017).

\section{Purpose and Hypotheses}

In order to create trust toward the agricultural industry, communicators need to make information more salient for message recipients, and one means of doing this is to establish the efficacy of competing appeal types in the context of agricultural issues. Messages with agricultural science information could be more relevant to the audience if these messages connect to consumer values. To understand the effect of value-oriented messages on the first stage of information processing, the purpose of this study was to assess how issue involvement and pre-existing attitudes influenced the nature of processing in the form of visual attention allocation to value-oriented versus scientific message frames. The following hypotheses guided the experiment:

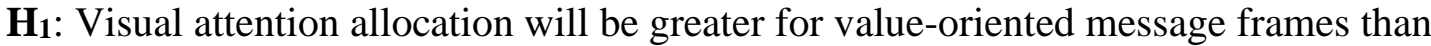
scientific reasoning message frames.

H2: Visual attention allocation will differ significantly due to issue involvement and the type of message frame.

H3: Visual attention allocation will differ significantly due to pre-existing attitudes and the type of message frame.

\section{Methods}

To address these hypotheses, an experiment was conducted where readers saw a series of advertorials on one of two topics embedded within a magazine presented on a computer monitor. Participants were recruited to take part in a magazine reading study with no mention of the nature of the advertising. Reading of the magazine was self-paced, and while reading, participants' visual attention to the stimuli was continuously recorded by a non-invasive eyetracking apparatus. The formal study design was a 2 (message frame: value-oriented vs. scientific reasoning) x 2 (message topic: antibiotic use in livestock and genetic modification in crops) $x 2$ (message repetition) mixed design experimental study to examine the impact of these 
factors on attention to magazine advertisements. Participants were randomly assigned to receive either value-oriented or scientific reasoning messages as the between-subjects factor.

Participants' issue involvement and pre-existing attitudes toward the two agricultural science practices were assessed through a pre-test and served as a between-subjects variable. Further, a subsequent within-subjects factor of message repetition was employed such that the researchers created two stimuli in each condition (i.e., the participants viewed two genetic modification messages and two antibiotic use in livestock messages) to minimize variation in a particular advertorial. Table 1 describes the messages the participants viewed by condition. To measure the dependent variable of visual attention allocation, eye tracking was selected to measure how long a participant allocated attention to the stimuli (i.e., Bucher \& Schumacher, 2006; Duchowski, 2007).

Table 1

Description of advertorials viewed by participant per condition

\begin{tabular}{ll}
\hline Value-Oriented Condition & Scientific Reasoning Condition \\
\hline Genetic Modification Version 1 & Genetic Modification Version 1 \\
Genetic Modification Version 2 & Genetic Modification Version 2 \\
Antibiotic Use in Livestock Version 1 & Antibiotic Use in Livestock Version 1 \\
Antibiotic Use in Livestock Version 2 & Antibiotic Use in Livestock Version 2 \\
\hline
\end{tabular}

Note: The order of appearance of the condition was randomized

\section{Participants}

The population for the study was parents who are the primary grocery purchaser for their home. This population was selected as prior research has found parents either lack trust of the agricultural sciences and the knowledge to make informed decisions about the agricultural science, and/or they are characterized as being the most concerned with the food they buy for their families (Hughner, McDonagh, Prother, Shultz, \& Stanton, 2007; Weatherell et al., 2003). A purposive sample of parents $(N=71)$ who are the primary grocery store shopper for their home was recruited from a large southwestern city and surrounding community. Participants were recruited from local Parent Teacher Associations, church groups, and sport groups through recruitment scripts and social media posts. Participants were provided a $\$ 50$ cash equivalent (VISA Gift Card) incentive for participation. A majority of participants were female $(n=53$, $77.9 \%$ ). All participants were parents with children in grades K-12 with an average of 1.69 ( $S D=$ .96) children in their household. Participants holding a graduate or professional degree $(n=28$, $41.2 \%)$ and a bachelor's degree $(n=17,25 \%)$ comprised the majority of participants. The participants were asked to select a category for their income. The most indicated income categories were $\$ 40,000$ to $\$ 49,999(n=10,14.9 \%), \$ 70,000$ to $\$ 79,999(n=10,14.9 \%)$, and $\$ 100,000$ to $\$ 149,9999(n=10,14.9 \%)$.

\section{Independent Variables}

Message Frame. Based on the participant's condition, they saw four advertorial messages that served to operationalize the two independent variables. An advertorial is a paid advertising execution technique where the message is presented in a format resembling the vehicle's editorial content (Crossen, 1988; Elliot, 1984). In the current study, the advertorial was placed in a magazine, to allow the message to be seen as an example of the editorial content. This format was chosen as Abrams and Soukup (2017) concluded short promotional messages 
"only garner attention and awareness and are insufficient to move the attitudinal needle" (p. 17). The longer text format of the advertorial may warrant longer, more systematic processing. The messages were created to mirror a previous campaign by Monsanto, a large agricultural science organization, whose main goal was to justify genetic modification of crops and restore brand image. The campaign had used similar advertorials, as well as videos, to promote brand trust and scientific literacy with the same call to action and tagline ("Be part of the conversation") in magazines such as Family Circle, Good Housekeeping, and Better Homes and Gardens (Altman, 2014). Each advertorial had the same amount of space allocated for headlines, copy (size and words), and visuals.

Message frame was operationalized in two levels: the value-oriented frame and scientific reasoning frame. Each of the advertorials included a narrated story that highlighted features of either the scientific reasoning or value-oriented frame. The scientific reasoning frame was operationalized via both textual and image elements within the advertorials. The text featured a strong emphasis on statistical evidence supporting claims from sources such as the FDA and USDA (Shen \& Bigsby, 2013). For example, one of the messages about genetic modification described the safety of the process: "Agencies such as the United States Department of Agriculture (USDA), conduct multiple rounds of testing to ensure GM foods are safe for consumption before farmers are able to plant them and grocers are able to sell them." These messages provided definitions, quantitative statistics, and information regarding the safety of antibiotic use in livestock and genetic modification of crops. Accompanying visuals portrayed the product (i.e., meat products, soybeans, and corn) or producers working on the farm and/or ranches. To operationalize the value-oriented frame, advertising copy and accompanying visuals were manipulated to increase the motivational salience of the message. Parents have shown interest in the food they buy their family, and this audience has been connected to the values of security, universalism, benevolence, and self-direction (Hughner et al., 2007; Wilkins, Gorham, \& Meyers, 2017). Similarly, researchers have indicated individuals are most likely to trust people who are similar to them such as friends and family (Fox \& Jones, 2009). The advertorials included body copy and images referencing these trusted sources. The visuals portrayed families eating at dinner tables and farmers caring for their animals. Additionally, a narrative was created focusing on testimonial stories to highlight the values of security, universalism, benevolence, and self-direction. For example, a message discussing the use of antibiotics in livestock explained:

I'm a mom, and I'm a rancher, I'm always worried about the health of both my children and my animals. Unfortunately, sometimes, they get sick. To help my children feel better, it is my responsibility to take them to the doctor, which sometimes results in a prescription for an antibiotic. It's the same with our animals.

Examples advertorials can be found in Figure 1. 


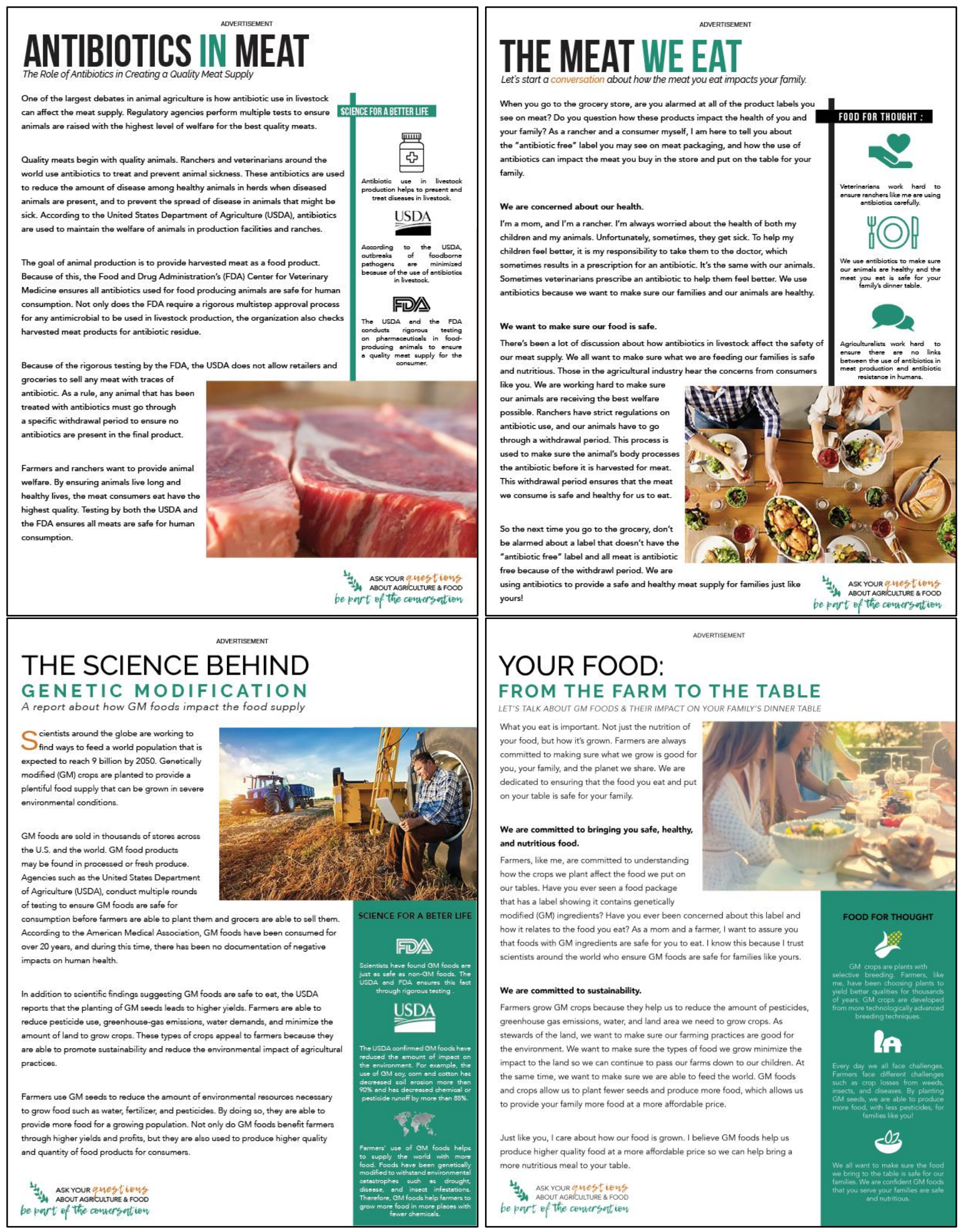

Figure 1. Example Advertorial Stimuli (Left, scientific reasoning; Right, value-oriented) 
To test the success of these manipulations, a pretest was conducted to verify differences between the scientific reasoning message frame and the value-oriented message frame. Undergraduate students from a large southwestern university were asked to participate in a quasi-experimental within-subjects design study, where the participants received all of the advertorials in a random order. The 38 participants were asked to rate their level of agreement on a Likert-type scale ( $1=$ Strongly Disagree, $5=$ Strongly Agree $)$ with the statements "I agree this message is written in a way that connects to my personal values," and "I agree this message is written in a way that highlights scientific aspects about the issue at hand." Two, two-way repeated measures ANOVAs were conducted to compare the message frame (value-oriented and scientific reasoning) by the message topic (GMO and antibiotic use) based upon the questions. The main effect of the first two-way repeated measures ANOVA showed a significant difference in the response to the question "I agree this message is written in a way that connects to my personal values" between the value-oriented message frame and the scientific reasoning message, $F(1,37)=6.76, p=.01, \eta^{2}=.15$. Similarly, the main effect of the second two-way repeated measures ANOVA showed a significant difference in the response to the question "I agree this message is written in a way that highlights scientific aspects about the issue at hand" between the value-oriented message frame and the scientific reasoning message, $F(1,37)=$ $5.18, p=.001, \eta^{2}=.26$. In addition, study participants responded to identical measures at the end of the final, current study, and the manipulation checks were also accepted.

Message Topic. The advertorials also systematically varied in terms of message topic such that each participant was assigned to receive two genetic modification messages and two messages about antibiotic use in livestock per condition as literature suggested these were two of the most concerning food production topics for parents (Hill \& Lynchenhaun, 2002; Hughner et al., 2007). For example, participants in the value-oriented condition saw two messages about genetic modification and two messages about antibiotics in livestock framed around the values of the participant; whereas, the participants in the scientific reasoning condition saw two messages about genetic modification and two messages about antibiotics in livestock framed around scientific facts. This was elected to better generalize message type to other issues, topics, message types (Thorson et al., 2012), and to account for message variance.

Pre-existing attitudes. To understand pre-existing attitudes, participants were asked to indicate their responses to the statement "I feel genetically modified foods are..." or "I believe meat from animals raised with antibiotics is..." depending on the message received. The index used a 5-point semantic differential scale with six bipolar adjective pairs: wrong/right, unacceptable/acceptable, bad/good, unfavorable/favorable, foolish/wise, and negative/positive. The measure was adapted from Zaichowsky's (1994) Personal Involvement Inventory (PII), which has been used in studies relating to understanding attitudes of the agricultural industry in Lundy (2004), Meyers (2008), and Goodwin (2013) studies. The internal reliability of the measure was $\alpha=.93$ for genetic modification and $\alpha=.96$ for antibiotic use in livestock.

Issue involvement. Issue involvement was measured using Nowak and Salmon's (1987) involvement with social issues scale. Prior research has suggested issue involvement has a relationship with motivation to process messages (von Borgstede, Andersson, \& Hansla, 2014; O'Keefe, 2008; Petty \& Cacioppo, 1986). The issue involvement regarding social issues scale was measured using is a 7-item, 5-point, semantic differential scale: important/unimportant, irrelevant/relevant, matters to me/doesn't matter to me, significant/insignificant, of no concern to melof concern to me, very meaningful to me, means nothing to me, interesting/not interesting, 
trivial/fundamental (Nowak \& Salmon, 1987). Internal reliability for genetic modification was $\alpha$ $=.92$ and $\alpha=.88$ for antibiotic use in livestock.

\section{Dependent Variable}

The effects of the independent variables were measured on the dependent variable of attention, operationalized through eye tracking. Eye tracking has been increasingly employed across a variety of fields including strategic communication to provide objective measures of visual attention allocation (Duchowski, 2007). Eye tracking rests on the assumption that the redirection of gaze to specific message elements reflects the overt act of attention allocation to elements within one's visual field. When gaze is redirected, objects of interest fall within the eye's fovea, where visual receptors are most dense and objects are seen with greatest visual acuity (Jacob, 1995). During these fixations, or brief periods where the eye is relatively still, information is taken in before gaze is redirected by short saccadic motion (Duchowski, 2007; Jacob, 1995). The duration of each fixation serves as an overt quantitative measure of depth of cognitive processing or interest in the element (Duchowski, 2007). The aggregate sum of each fixation duration, or total fixation duration, can serve as an operational measure of attention allocation to the message or message elements. In this study, the amount of time fixated on the advertisements served as the measure of visual attention allocation.

\section{Procedure and Protocol}

To participate, participants were sent a link to complete an online pre-test via Qualtrics before coming to the eye tracking laboratory. The pre-test questionnaire included questions related to the participants' level of issue involvement and pre-existing attitude toward genetic modification and antibiotic use in livestock. A pre-test was chosen as the effect of priming was not a concern as the differences in the evaluation were between message type (i.e., scientific reasoning vs. value-oriented) and not attention placed on agricultural science information versus non-agricultural science information. The data were collected in individual sessions in an eye tracking, laboratory setting. An eye tracking experiment was chosen as it allows for a greater level of control of the experiment (Duchowski, 2007). Although the laboratory setting decreases ecological validity, the increased control allows for higher internal validity and allows the researchers to "uncover similarities of viewing patterns of large groups of viewers" (Duchowski, 2007, p. 160). Upon arrival to the lab, each of the participants was asked to sit approximately 24 inches from a 27-inch computer monitor. A Tobii X2-60 Eye-Tracker control unit was located just below the screen to monitor the participant's gaze during the experiment. This type of apparatus is noninvasive as it is no different than viewing a computer screen. Tobii studio software was used to collect the gaze data at a sampled rate of $60 \mathrm{hz}$.

Before the presentation of the magazine, the above software and apparatus was used to calibrate each of the participant's gaze using a calibration procedure. After the calibration procedure, the participants were randomly assigned to view a version of a 25-page magazine from a section of the April 2017 version of Good Housekeeping. The magazine was selected for its target audience of the primary grocery store buyer for the families with school-aged children (typically married females), and it had content regarding food. Additionally, the aforementioned examples for the study stimuli originally appeared in Good Housekeeping. Participants were asked to browse the magazine for quality (up to 30 minutes. The magazine was divided into four equal sections (number of pages, advertisements, and editorial content), with each of the four sections containing an advertorial and four foil (control) advertisements. This study was a part of a larger project, and to understand effects of the message on attitude, a between-subjects 
distribution of stimuli was chosen. Participants were randomly assigned to receive either valueoriented or scientific reasoning messages. Although Tobii Studio software does not allow for randomization as seen in traditional questionnaire design, a rotation system was used to counter error effects. This system has been utilized in past eye tracking research and was recommended based on prior research (Duchowski, 2007). Participants were then randomly assigned to one of eight rotation orders.

\section{Data Collection, Analysis and Limitations}

For the questionnaire, the researcher recorded the data through Qualtrics. The eye tracking data was gathered through the Tobii Studio (v. 3.4.7) software system, exported into Microsoft Excel, and then imported into SPSS v.24. This study used both descriptive and inferential statistical procedures for ANOVAs outlined by Field (2012). In order to understand the relationships between the variables, a significance level of $p<.05$ was established a priori. Additionally, data were also inferred as 'approaching significance' with a description of the effect size. Wasserstein and Lazar (2016) explained "scientific conclusions and business or policy decisions should not be based only whether a $p$-value passes a specific threshold," (p. 131) and instead, researchers should evaluate the results based on many contextual factors including inferences and effect size, the design of the study, the quality of the measurements, the phenomenon understudy, and the validity of the assumptions. Thorson et al. (2012) described a report of non-significant findings with substantial effect sizes may allow the reader to "assess whether the non-significant result is the result of low power" (p. 124) as seen in laboratory based studies. Although the small sample size is a limitation of this study, the results showcase how specific messages elicit attention allocation from groups of people. This data set is part of a larger study; however, these hypotheses were analyzed and inferred separate from the rest of the data.

\section{Results \\ $\mathrm{H}_{1}$ : Visual attention allocation will be greater for value-oriented message frames than scientific reasoning message frames.}

The first hypothesis $\left(\mathrm{H}_{1}\right)$ predicted value-oriented messages in magazine advertisements would elicit more visual attention allocation than scientific elements. To address this hypothesis, a mixed-measures ANOVA was used to calculate the effect of message frame on total fixation duration in seconds on the advertorials. The message topic (genetic modification, antibiotic use) and the message repetition served as the within-subjects variable, and the message frame served as the between-subjects variable. The main effect of message frame was found to be significant, $F(1,66)=4.45, p=0.039, \eta^{2}=.063$, indicating the value-oriented messages elicited an overall longer fixation duration (seconds) on the messages (Value-Oriented: $M=16.80 ; S D=12.14$; Scientific Reasoning: $M=9.82, S D=9.94)$. Figure 2 provides a depiction of the visual attention allocated (seconds) to the GM version 1 advertorials. Hypothesis 1 was supported. 


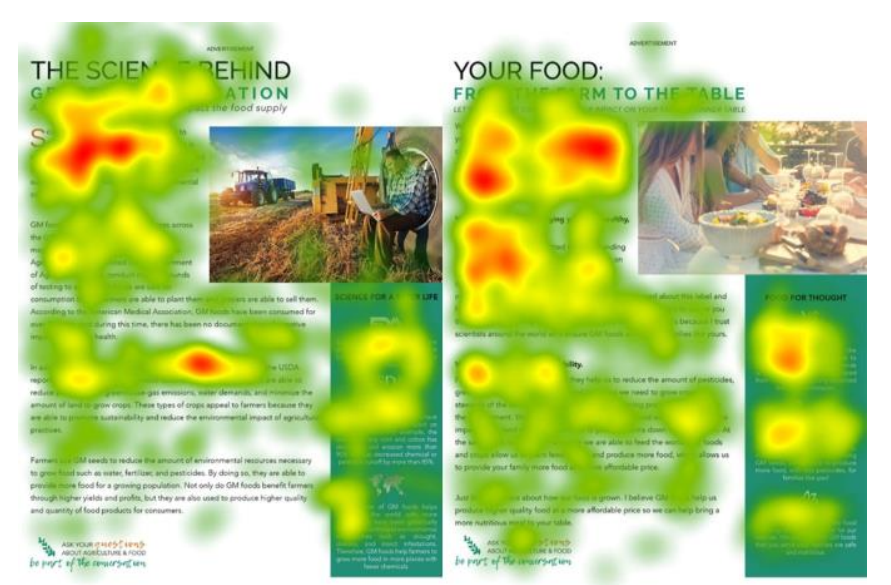

Figure 2. Heat maps depicting visual attention allocation to genetic modification advertorials (Left, Scientific Reasoning; Right, Value-Oriented).

\section{$\mathrm{H}_{2}$ : Visual attention allocation will differ significantly due to issue involvement and the type of message frame.}

$\mathrm{H} 2$ was tested by two factorial ANOVAs where total fixation duration on the genetic modification messages served as the dependent variable, whereas issue involvement (low, high) and message frame (scientific reasoning, value oriented) served as the independent variables. Two ANOVAs were conducted as issue involvement was specific to the topic of the advertorial being viewed based on their message topic. Specifically, the statistical analyses separately examined visual attention to the messages about genetic modification and antibiotic use in livestock because the participants' level of involvement would vary by topic (e.g., someone may have high involvement on one topic and not the other, and vice-versa).

To categorize issue involvement into groups (low, high), median splits were conducted on issue involvement to genetic modification (Median $=3.78$ ) and issue involvement to antibiotic use in livestock (Median $=3.79$ ). An independent samples t-test confirmed differences for the two groups, $t(64)=-10.89, p<.01$. Participants categorized as low issue involvement $(n$ $=36$ ) to genetic modification had a mean issue involvement score of $3.18(\mathrm{SD}=.54)$; those who were categorized as high issue involvement to genetic modification $(n=30)$ had an average score of $4.48(\mathrm{SD}=.39)$. Similarly, a median split (Median $=3.79)$ was also calculated with issue involvement to antibiotic use in livestock. An independent samples $t$-test confirmed differences for the two groups, $t(65)=-9.94, p<.01$.Participants categorized as low issue involvement to antibiotic use in livestock $(n=40)$ had a mean issue involvement to antibiotic use in livestock score of $3.31(\mathrm{SD}=.52)$; those who were categorized as high issue involvement to antibiotic use in livestock $(n=27)$ had a mean issue involvement score of $4.50(\mathrm{SD}=.40)$.

In the first factorial ANOVA, the interaction effect between issue involvement to genetic modification and message frame was significant for messages about genetic modification, $F(1,62)=3.02, p=.02, \eta^{2}=.03$. Figure 4 depicts total fixation duration on the differing message frames as a function of issue involvement to genetic modification. As Figure 3 illustrates, when readers had low issue involvement to genetic modification, the value-oriented frame elicited greater attention. In contrast, the opposite pattern was observed for readers with high issue involvement, as they allocated greater attention to messages with the scientific reasoning frame. Table 2 presents descriptive statistics for the competing message frames a function of issue involvement. 
Table 2

Estimated Marginal Means of Total Fixation Duration by Message Frame and Level of Issue Involvement (seconds)

\begin{tabular}{|c|c|c|c|c|}
\hline & \multicolumn{2}{|c|}{ Low Involvement } & \multicolumn{2}{|c|}{ High Involvement } \\
\hline & Mean & $\mathrm{SD}$ & Mean & SD \\
\hline \multicolumn{5}{|l|}{ Scientific Reasoning Message Frame } \\
\hline GM & 15.26 & 3.72 & 22.79 & 5.13 \\
\hline Antibiotic Use in Livestock & 17.43 & 3.58 & 25.26 & 12.67 \\
\hline \multicolumn{5}{|l|}{ Value Oriented Message Frame } \\
\hline GM & 25.69 & 4.87 & 21.83 & 4.10 \\
\hline Antibiotic Use in Livestock & 28.82 & 3.70 & 19.41 & 4.11 \\
\hline
\end{tabular}
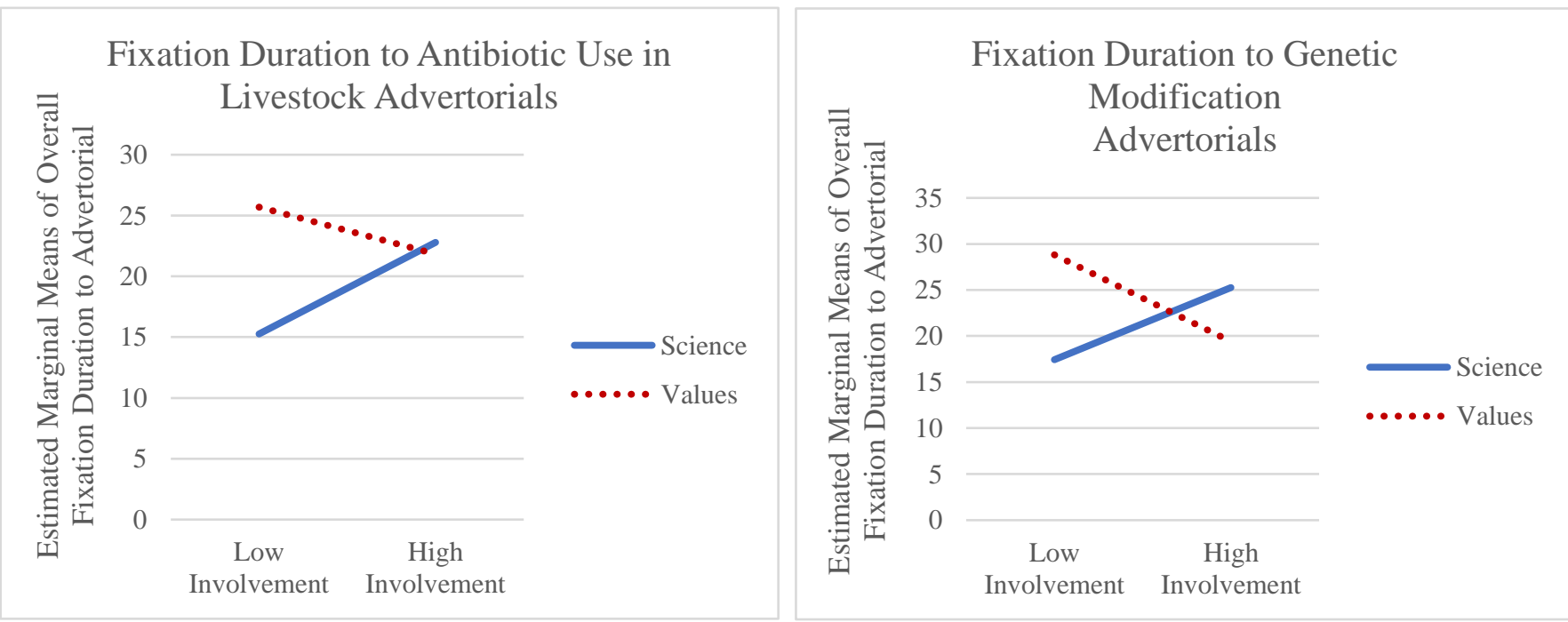

Figure 3. Visual representation of estimated marginal means of fixation duration, issue involvement, and message frame per advertorial

Likewise, a second factorial ANOVA was conducted to understand the effect of issue involvement and message frame on total fixation duration of the antibiotic use in livestock messages. Again, total fixation duration served as the dependent variable, whereas issue involvement to antibiotic use in livestock and condition served as the independent variables. The interaction effect between issue involvement and message frame approached significance, $F(1,66)=3.59, p=.06, \eta^{2}=.06$. The same pattern was observed here as in the previous test. As seen in Table 2, readers with low involvement had longer total fixation durations with the value-oriented message frame $(M=28.82, S D=3.69)$ than the scientific message frame $(M=17.43 S D=3.57)$. Thus, $\mathrm{H} 2$ was supported.

\section{$\mathrm{H}_{2}$ : Visual attention allocation will differ significantly due to pre-existing attitudes and the type of message frame.}

H3 was tested by two factorial ANOVAs where total fixation duration on the genetic modification messages served as the dependent variable, whereas pre-existing attitudes (low, 
high) and message frame (scientific reasoning, value oriented) served as the independent variables. Two ANOVAs were conducted as pre-existing attitudes was specific to the topic of the advertorial being viewed based on their message topic. Specifically, the statistical analysis examined visual attention to the messages about genetic modification and antibiotic use in livestock separately because the participants' level of pre-existing attitudes would vary by topic.

To categorize pre-existing attitudes into groups (low, high), a median split was conducted on pre-existing to genetic modification (Median $=2.76$ ) and pre-existing attitudes to antibiotics use in livestock (Median =2.62). An independent samples t-test confirmed differences for the two groups, $\mathrm{t}(64)=-11.71, p<.01$. Participants categorized as low pre-existing attitudes $(n=32)$ to genetic modification had a mean pre-existing attitude score of $1.19(S D=.58)$; those who were categorized as high pre-existing attitudes to genetic modification $(n=34)$ had an average score of $3.55(S D=.56)$. Similarly, a median split was also calculated with pre-existing attitudes to antibiotic use in livestock. Participants categorized as low pre-existing attitudes use in livestock $(n=34)$ had a mean pre-existing attitudes to antibiotic use in livestock score of 1.76 $(S D=.11)$; those who were categorized as high pre-existing attitudes to antibiotic use in livestock $(n=33)$ had a mean issue involvement score of $3.50(S D=.58)$. An independent samples t-test confirmed differences for the two groups, $t(65)=-12.09, p<.01$.

Two factorial ANOVAs were conducted to understand the effect of pre-existing and message frame on total fixation duration to the messages. In the first factorial ANOVA, total fixation duration served as the dependent variable; whereas pre-existing attitudes to genetic modification and condition served as the independent variable. The interaction effect between pre-existing attitudes for genetic modification and message frame on total fixation duration was non-significant, $\mathrm{F}(1,56)=.077, p=.78$. In the second factorial ANOVA, total fixation duration served as the dependent variable; whereas, pre-existing attitudes to antibiotic use in livestock and condition served as the independent variable. The interaction effect of pre-existing attitudes to antibiotic use in livestock and message frame on total fixation duration was non-significant, $\mathrm{F}(1,65)=.284, p=.59$. Thus, hypothesis 3 was not supported.

\section{Conclusions, Implications, and Recommendations}

Research has suggested the American public has a limited understanding of agricultural science information. Concurrently, agricultural scientists are struggling to communicate with audience members who receive a large amount of information daily. To bridge the gap between scientific and public opinion, scientific information should be made relevant through enhanced saliency in messaging. Communicators have suggested using value-oriented frames to connect scientific information to personal values to distribute more relevant scientific information to public audiences (Krause et al., 2015; Ruth \& Rumble, 2017). The prior literature suggested that although research has explored selective attention in response to processing, little research has explored selective attention and its role in the processing of scientific information. The results of this study provided empirical evidence to suggest how agricultural science information may become more salient to resonate with the public (i.e., Bucchi, 1998; Scheufele, 2013). The analysis of how two different types of message frames attract attention shows that an increase in motivational saliency through values leads to higher levels of visual attention allocation to low involvement audiences; however, with high involvement audiences, the individual preferred the scientific information. Thus, the findings of the paper provide evidence for strategic messaging in the agricultural sciences. Specifically, H1 suggested value-oriented message frame elicit more attention allocation than the scientific reasoning message frame. However, looking more 
granularly, attention to message frame also appears to differ by issue involvement (H2) as low issue involvement groups appear to attend longer to the value-oriented message frame than high involvement participants. This finding suggests that when individuals find the content to be motivationally relevant (i.e., low involvement participants are motivated by values; high involvement participants are motivated by science), they place more attention on the content. The results of this study provide evidence of strategic audience engagement through agricultural messages by providing value-oriented information to low involvement audiences and scientific information to high involvement audiences.

Overall, participants were more likely to place attention on value-oriented message frames as opposed to the scientific reasoning message frames. Individuals encounter a great deal of information on a daily basis, and to cope with the influx of information, individuals have developed mechanisms to prioritize aspects of messages (Gong \& Cummins, 2016). Specifically, individuals tend to ignore information inconsistent with an attentional goal (Folk et al., 1992), or information that does not support their prior beliefs and/or attitude (i.e., Smith et al., 2007). In the current study, the value-oriented message frame served to increase motivational saliency because the individual is exposed to information that affects them personally or their families. When the values were present in the message (e.g., the value-oriented frame), the messages elicited higher levels of visual attention allocation. Similarly, the scientific reasoning message may have received less visual attention allocation due to not being consistent with the viewer's attentional goal (Smith et al., 2007). In the current experiment, the majority of the Good Housekeeping magazine content dealt with issues pertaining to the home and family. When exposed to scientific reasoning framed advertorials, the viewer placed less attention on the advertorials as the individual chose to place less attention the information that was inconsistent with their viewing habits (e.g., Folk et al., 1992). Further, higher levels of scientific reasoning (i.e., contributions and statistics from the USDA as opposed to a narrative) may have been an impact of the lack of continuation of reading of the scientific reasoning frame. Instead of reading a story, the reader may have lost interest due to lack of knowledge or the ability to process the information. This heeds to the practical suggestion that when providing issue-based messaging, the message must align with the individual's prior viewing habits in order to be processed.

In a more granular analysis, exploration of issue involvement and pre-existing attitudes revealed issue involvement had approaching statistical significance interactions $\left(p=.08, \eta^{2}=\right.$ $.05)$ on visual attention allocation. However, pre-existing attitudes did not elicit differences in visual attention allocation. The analysis of the figures suggested participants with low issue involvement placed a longer amount of visual attention allocation on the value-oriented message; however, high involvement participants placed relatively equal amounts of visual attention on both the value-oriented and scientific reasoning message. Participants with high levels of involvement to the topic were already motivated to read the content as they have a high involvement with it, and thus, did not need the value frame to entice them to read it. This is consistent with prior literature that has suggested that with high involvement audience (i.e., those with ties to food and agriculture), message frames should be scientific in nature (Fischer et al., 2017). However, the results from the low issue involvement participants further support the idea that value-oriented messages attempt to increase motivational saliency by making the information more relevant to the consumer. Because food products and scientific information are characterized as low involvement products (Dodds et al., 2008), the value-oriented frame provides an avenue to increase in saliency leading to higher processing of the issue, product, and information with low involvement audiences. These results may be an indicator that when 
perceived personal relevance is high, the participant may experience a controlled attention response to the information, resulting in longer visual attention allocation. The nature of the higher visual attention allocation was consistent with other studies of low-involvement advertisements. Specifically, Gong and Cummins (2016) suggested low involvement type products must be advertised with an increase in perceived involvement to make consumers aware of connections and personal references between the message and its reader.

The results of this study suggest the value-oriented message frame elicited more visual attention allocation from low involvement audiences. Those participants with low issue involvement held longer fixation durations to the value-oriented messages. The value-oriented message frame increases motivational saliency and captures the attention of those unfamiliar and with low to neutral issue involvement with the scientific topics. Researchers have suggested scientific information needs to be more relevant to the average public audience (Bucchi, 1998; Scheufele, 2013), and this study suggests value-oriented messages elicit higher levels of visual attention allocation. The first step in information processing is attention allocation. Within information processing, attention allocation occurs first, then information processing and attitude development (Lang, 2000; Smith et al., 2007; Thorson et al., 1992). By capturing viewing engagement, communicators can better reach their audiences with their content and information. Perhaps the key indicator in value-oriented information is the increase in motivational saliency and personal involvement - showing the participants why they should care about the information.

The study provides evidence to suggest an increase in motivational salience has the potential to increase visual attention allocation toward agricultural science messages. Theoretically, selective attention is a major driver in how attitudes and information are processed. Without the ability to view information, individuals are unable to process the information. One future study should be conducted with a larger sample size. A future study should evaluate the effect of the motivational saliency on attitude toward the advertisement. Further, a pre-test, post-test study could compare attitude change of the viewer. Methodologically, this study provides a starting point for developing messages in agricultural communications that capture attention. Little research has used the eye tracking tool to understand the effect of message development in the agricultural social sciences. Eye tracking and monitoring visual attention allocation allow researchers to not only understand the sequence of gaze or viewing that occurs when a participant views a stimulus, but also the duration of time spent viewing and the specific areas of interest. Continued research within eye tracking could confirm what aspects of the message elicit higher visual attention allocation. For example, literature suggested scientific knowledge may impact the ability to process. Future research may be used to understand how this construct relates to attention allocation.

Strategic communication and framing with issue-based advertising is necessary in the agricultural industry. Many consumers find information from social media, television, print advertisements, out of home advertisements, and even food labels. Information embedded within these forms of communication have impacted public perception of the issues at hand (Rummo, 2016). This study's results support the agricultural industry-based recommendations that valueoriented message frames should be added into advertisements and communication materials about the agricultural industry with low involvement audiences. Value-oriented messages provide a way for agriculturalists to capture attention of low involvement consumers. With audiences with high involvement to the topic, scientific oriented messages may be the route for the target. However, there is still much room for future research in this area. First, while 
demographic targeting is essential to strategic communication, the agricultural community needs to do a better job of understanding the psychographics of their audiences (i.e., attitudes, beliefs, and values) and tailor communication to these needs. Once psychographics have been understood about the targeted audience, more narratives and storytelling should be used in agricultural communication messages to continue to retain the attention of viewers. In addition to the practical suggestions, the authors suggest more research in the realm of narrative inquiry and storytelling using agricultural science.

\section{References}

Abrams, K. \& Meyers, C. (2012). From opposite corners: Comparing persuasive message factors and frames in opposing organizations' websites. Journal of Applied Communications, 96(1), 54-67. https://doi.org/10.4148/1051-0834.1150

Abrams, K., \& Soukup, C. (2017). Matching local food messages to consumer motivators: An experiment comparing the effects of differently frames messages. Journal of Applied Communications, 101(4), 1-19, https://doi.org/10.4148/1051-0834.1297

Abrahamse, E., Majerus, S., Fias, W., \& van Dijck, J. (2015). Editorial: Turning the mind's eye inward: The interplay between selective attention and working memory. Frontiers in Human Neuroscience, 9(616). doi: 10.3389/fnhum.2015.00616

Altman, M. (2014). Monsanto appeals directly to consumers in new ad campaign. St. Louis Public Radio. Retrieved from http://news.stlpublicradio.org/post/monsanto-appealsdirectly-consumers-new-ad-campaign\#stream/0

Bayer Corporation. (2016). Bayer forum narrows gap between and food production. $P R$ Newswire. Retrieved from http://www.prnewswire.com/news-releases/bayer-forumnarrows-gap-between-public-and-food-production-300228494.html

Blake, P. (2016). Obama Signs Bill Mandating GMO Labeling. ABC News. Retrieved from http://abcnews.go.com/US/obama-signs-bill-mandating-gmolabeling/story?id=41004057

Borgida, E., \& Howard-Pitney, B. (1983). Personal involvement and the robustness of perceptual salience effects. Journal of Personality and Social Psychology, 45(3), 560-570. doi:10.1037/0022-3514.45.3.560

Brader, T. (2006). Campaigning for hearts and minds: How emotional appeals in political ads work. Chicago, IL: University of Chicago Press.

Brewer, P. B., \& Gross, K. (2005). Value, framing, and citizens' thoughts about policy issues: effects on content and quantity. Political Psychology, 2(6), 929-948. https://doi.org/10.1111/j.1467-9221.2005.00451.x

Bruce, N. D., \& Tsotsos, J. K. (2009). Saliency, attention, and visual search: An information theoretic approach. Journal of vision, 9(3), 5-5. doi:10.1167/9.3.5

Bucchi, M. (1998). Science and the media: Alternative routes of scientific communication. London: Routledge.

Bucher, H. \& Schumacher, P. (2006). The relevance of attention for selecting news content. An eye-tracking study on attention patterns in the reception of print and online media. Communications, 31(3), 347-368. https://doi.org/10.1515/COMMUN.2006.022

Center for Food Integrity. (2014). Cracking the code on food issues: Insights from moms, millenials and foodies. The Center for Food Integrity. Retrieved from http://s3.amazonaws.com/www.foodintegrity.org/wpcontent/uploads/2015/08/CFI2014ResearchBook.pdf

Celsi, R. L. \& Olson, J. C. (1988). The role of involvement in attention and comprehension processes. Journal of Consumer Research, 15(2), 210-224. http://dx.doi.org/10.1086/209158 
Conway, G., \& Waage, J. (2010). Why science is important for innovation. Development Outreach, 12(1), 13-15. http://dx.doi.org/10.1596/1020-797X_12_1_13

Corner, A., Whitmarsh, L., and Xenias, D. (2012). Uncertainty, scepticism and attitudes towards climate change: Biased assimilation and attitude polarisation. Climatic Change, 114(3), 463-478. http://dx.doi.org/10.1007/s10584-012-0424-6

Crossen, C. (1998). Proliferation of 'advertorials' blurs distinction between news and ads. Wall Street Journal, 29

Cummins, R.G. (2017). Eye tracking. In J. Matthes (Ed.), International encyclopedia of Communication Research Methods. Hoboken, NJ: Wiley-Blackwell.

Dixon, G., Hmielowski, \& Ma, Y. (2017). Improving climate change acceptance among U.S. conservatives through value-based message targeting. Science Communication, 39(4), 520-534. doi: 10.1177/1075547017715473.

Dodds, R. E, Tseëlon, E., \& Weitkamp, E. L. C. (2008). Making sense of scientific claims in advertising: A study of scientifically aware consumers. Public Understanding of Science, 17(2), 211-230. doi: 10.1177/0963662506065559.

Duchowski, A. (2007). Eye tracking methodology: Theory and practice ( $2^{\text {nd }}$ ed.) London: Springer.

Duncan, D. W., \& Broyles, T. W. (2006). A comparison of student knowledge and perceptions toward agriculture before and after attending a governor's school for agriculture. NACTA Journal, 50(1), 16-21. Retrieved from https://www.nactateachers.org/attachments/article/311/Duncan_March_2006_NACTA_J ournal-4.pdf

Elliot, S. J. (1984). Advertorials: Straddling a fine line in print. Advertising Age, 3: 36-37.

Entman, R. M. (1993). Framing: Toward clarification of a fractured paradigm. Journal of Communication,43(4), 51-58. https://doi.org/10.1111/j.1460-2466.1993.tb01304.x

Field, A. (2012). Discovering statistics using IBM SPSS Statistics ( $4^{\text {th }}$ Ed.). London, UK: Sage

Fischer, L. M., Cummins, R. G., Gilliam, K., Baker, M., Burris, S., \& Irlbeck, E. (2018). Examining the critical moments in information processing of water conservation videos within young farmers and ranchers: A psychophysiological analysis. Journal of Agricultural Education, 59(2), 1-15, https://doi.org/10.5032/jae.2018.02001

Folk, C. L., Remington, R. W., \& Johnston, J. C. (1992). Involuntary covert orienting is contingent on attentional settings. Journal of Experimental Psychology: Human Perception and Performance, 18(4), 1030-1044. doi: 10.1037/0096-1523.18.4.1030

Fox, S., \& Jones, S. (2009). The social life of health information. Washington, DC: Pew Internet \& American Life Project.

Funk, C., \& Raine, L. (2015). Public and scientist's view on science and society. Pew Research Center. Retrieved from http://www.pewinternet.org/2015/01/29/public-and-scientistsviews-on-science-and-society/

Goodwin, J. N. (2013). Taking down the walls of agriculture: Effect of transparent communication and personal relevance on attitudes and trust within the Elaboration Likelihood Model (Doctoral Dissertation). Retrieved from http://ufdcimages.uflib.ufl.edu/UF/E0/04/53/18/00001/GOODWIN_J.pdf.

Goodwin, J. N., Chiarelli, C., \& Irani, T. (2011). Is perception reality? Improving agricultural messages by discovering how consumers perceive messages. Journal of Applied Communications, 95(3), 21-33. https://doi.org/10.4148/1051-0834.1162 
Gong, Z. \& Cummins, R. G. (2016, August). Processing capacity in visual search:

The impact of visual salience and involvement on attention. Paper presented to the annual meeting of the Association for Education in Journalism and Mass Communication, Minneapolis, MN.

Gorham, L. M., Rumble, J. N., \& Holt, J. (2015). The impact of local: Exploring availability and location on food buying decisions. Journal of Applied Communications, 99(2), 30-43. https://doi.org/10.4148/1051-0834.1046

Graham, F. K. (1979). Distinguishing among orienting, defense, and startle reflexes. In H. D. Kimmel., E. H. VanOlst, \& J. F. Orlebeke (eds.), The Orienting Reflex in Humans (pp. 137-167). Hillsdale, NJ: Erlbaum.

Guido, G. (2001). The Salience of Marketing Stimuli: An Incongruity-Salience Hypothesis on Consumer Awareness. Norwell, MA: Kluwer Academic Publishers.

Hartz, J., \& Chappell, R. (1997). Worlds apart: How the distance between science and journalism threatens America's future. Nashville, TN: First Amendment Center.

Hill, H. \& Lynchenhaun, F. (2002). Organic milk: Attitudes and consumption patterns. British Food Journal, 104(7), 526-234. https://doi.org/10.1108/00070700210434570

Hughner, R. S., McDonagh, P., Prothero, A., Shultz, C. J., \& Stanton, J. (2007). Who are organic food consumers? A compilation and review of why people purchase organic food. Journal of Consumer Behaviour, 6(2-3), 94-110. https://doi.org/10.1002/cb.210

Jacob, R. K. (1995). Eye tracking in advanced interface design. In W. Barfield \& T.A. Furness III (Eds.), Virtual environments and advanced interface design (pp. 258-290). New York: Oxford University Press.

James, W. (1890). The Principles of Psychology. New York, NY: Holt.

King, A. E. H., \& Baker, L. M. (2018). A perplexing process: Understanding how agricultural producers process best management practice information. Journal of Applied Communications, 102(3), 1-17. https://doi.org/10.4148/1051-0834.2190

Klink, P. C., Jengtgens, P., \& Lorteije, J. A. (2014). Priority maps explain the role of value, attention, and salience in goal-oriented behavior. Journal of Neuroscience, 34(42), 13867-13869. doi:10.1523/JNEUROSCI.3249-14.2014

Krause, A., Meyers, C. Irlbeck, E., \& Chambers, T. (2016). The value of a Youtube video: A content analysis of the message sensation value of labeling videos. Paper presented at the National American Association of Agricultural Education meeting. Kansas City, MO.

Lake, R. (2016). Grocery Shopping Statistics: 23 Fun Size Facts to Know. Credit Donkey. Retrieved from: https://www.creditdonkey.com/grocery-shopping-statistics.html

Lang, A. (2000). The limited capacity model of mediated message processing. Journal of Communication, 50(1), 46-70. doi https://doi.org/10.1111/j.14602466.2000.tb02833.x

Lee, C., Scheufele, D. A., \& Lewenstein, B. V. (2005). Public attitudes toward emerging technologies: Examining the interactive effects of cognitions and affect on public attitudes toward nanotechnology. Science Communication, 27(2), 240-267. doi: $10.1177 / 1075547005281474$

Lundy, L. K. (2004). Globally speaking: The effect of internal message frames on attitudes and cognitive processing focused on internationalizing agricultural extension within the elaboration likelihood model. Unpublished doctoral dissertation, University of Florida, Gainesville. 
MacInnis, D. J. \& Jaworksi, B. J. (1989). Information processing from advertisements: Toward an integrative framework. Journal of Marketing, 53(4), 1-23. doi: 10.2307/1251376.

Meyers, C. A. (2008). The agricultural angle: Effect of framing agricultural biotechnology messages on attitudes and intent to publish within the Elaboration Likelihood Model (Doctoral Dissertation). Retrieved from http://gradworks.umi.com/33/34/3334488.html

National Academies of Sciences, Engineering, and Medicine. (2017). Communicating Science Effectively: A Research Agenda. Washington, DC: The National Academies Press. doi: $10.17226 / 23674$.

Nowak, G. J., \& Salmon, C. T. (1987). Measuring involvement with social issues. Paper presented at the annual meeting of the Association for Education and Journalism and Mass Communication, San Antonio, TX.

Ohman, A. (1979). The orienting response, attention, and learning. An information processing perspective. In H. D. Kimmel, E. H., van Olst, \& J. F. Orlebeke (Eds.) The orienting reflex in humans (pp. 443-471). Hillsdale, NY: Lawrence Erlbaum Associates.

O’Keefe, D. J. (2008). Elaboration likelihood model. In W. Donsbach, et al. (eds.), International Encylocpedia of Communications. Oxford: Blackwell.

Pecher, E., Bernauer, T., \& Mayer, F. (2018). Beyond political ideology: The impact of attitudes towards government and corporations on trust in science. Science Communication, 4(3), 291-313. doi: 10.1177/1075547018763970

Peters, H. P. (2013). Gap between science and media revisited: Scientists as public communicators. Proceedings of the National Academy of Sciences of the United States of America, 110(Suppl 3), 14102-14109. http://doi.org/10.1073/pnas.1212745110

Petty, R. E., \& Cacioppo, J. T. (1979). Issue involvement can increase or decrease persuasion by enhancing message-relevant cognitive responses. Journal of Personality and Social Psychology, 37(10), 1915-1926. http://dx.doi.org/10.1037/0022-3514.37.10.1915

Petty, R. E. \& Cacioppo, J. T. (1986). Communication and persuasion: Central and peripheral routes to attitude change. New York: Springer/Verlag.

Roberts, T. G., Harder, A., \& Brashears, M. T. (Eds). (2016). American Association for Agricultural Education national research agenda: 2016-2020. Gainesville, FL: Department of Agricultural Education and Communication. Retrieved from http://aaaeonline.org/resources/Documents/AAAE_National_Research_Agenda_20162020.pdf

Rumble, J, \& Irani, T. (2016). Opening the doors to agriculture: The effect of transparent communication attitude. Journal of Applied Communications, 100(2), 57-72. https://doi.org/10.4148/1051-0834.1030

Rumble, J., Rogers-Randolph, T. M., \& Buck, E. B. (2019). Should livestock images provide historical reference or modern reality? An examination of the influence of livestock communication on attitude. Journal of Applied Communications, 103(2), 1-15. doi: 10.4148/1051-0834.2263

Ruth, A. M., Lundy, L. K., \& Park, T. D. (2005). Glitz, glamour, and the farm: Portrayal of agriculture as the simple life. Journal of Applied Communications, 89(4), 21-37. https://doi.org/10.4148/1051-0834.1311

Ruth, A., Lundy, L., Telg, R., \& Irani, T. (2005). Trying to relate media relations training needs of agricultural scientists. Science Communication, 27(1), 127-145. doi: $10.1177 / 1075547005278347$ 
Ruth, T. K. (2015). The influence of persuasive communication on Florida consumers' change in attitude and change in risk perception of genetically modified food. (Masters' Thesis). Retrieved from http://www.piecenter.com/wpcontent/uploads/2015/09/Ruth_Thesis_Final_Clearance.pdf

Ruth, T., \& Rumble, J. (2018). What's in a name? Influence of persuasive communication on Florida consumers' attitude toward genetically modified food. Journal of Applied Communications, 101(2), 72-85. https://doi.org/10.4148/ 1051-0834.1006

Ruth, T. K., Gay, K. D., Rumble, J. N., \& Rodriguez, M. T. (2015). Influences on undergraduate students' opinion toward genetically modified food. Paper presented at the national meeting of the American Association for Agricultural Education, San Antonio, TX.

Scheufele, D. A. (1999). Framing as a theory of media effects. Journal of communication, 49(1), 103-122. doi:10.1111/j.1460-2466.1999.tb02784.x

Scheufele, D. (2013). Communicating science in social settings. Proceedings of the National Academy of Sciences of the United States of America, 110, 14040-14047. https://doi.org/10.1073/pnas.1213275110

Scott, S. E., Inbar, Y., \& Rozin, P. (2016). Evidence for absolute moral opposition to genetically modified food in the United States. Perspectives of Psychological Science, 11(3), 315324. doi:10.1177/1745691615621275

Smith, S. M., Fabrigar, L. R., Powell, D. M., \& Estrada, M. J. (2007). The role of informationprocessing capacity and goals in attitude-congruent selective exposure effects. Personality and Social Psychology Bulletin, 33(7), 948-960. doi:10.1177/0146167207301012

Shen, L., \& Bigsby, E. (2013). The effects of message features: Content, structure, and style. In J.P. Dillard \& L. Shen (eds.), The Sage Handbook of Persuasion: Developments in Theory and Practice (pp. 20-35). Thousand Oaks, CA: Sage.

Shen, F., \& Edwards, H. H. (2005). Economic individualism, humanitarianism, and welfare reform. A value-based account of framing effects. Journal of Communication, 55(4), 795-809. doi:10.1111/j.1460-2466.2005.tb03023.x

Thorson, E., Chi, A. \& Leavitt, C. (1992). Attention, memory, attitude, and conation: A test of the advertising hierarchy. Advances in Consumer Research, 19, 366-379. Retrieved from: http://www.acrwebsite.org/volumes/7323/volumes/v19/NA-19

Thorson, E., Wicks, R., \& Leshner, G. (2012). Experimental methodology in journalism and mass communication research. Journalism and Mass Communication Quarterly, 89(1), 112-124. doi:10.1177/1077699011430066

Verbeke, W. (2005). Agriculture and the food industry in the information age. European Review of Agricultural Economics, 32(3), 347-268. doi:10.1093/eurrag/jbi017

Verbeke, W., \& Ward, R. W. (2006). Consumer interest in information cues denoting quality, traceability and origin: An application of ordered profit models to beef labels. Food Quality and Preference, 17(6), 453-467. doi:10.1016/j.foodqual.2005.05.010

von Borgstede, C., Andersson, M., \& Hansla, A. (2014). Value-congruent information processing: the role of issue involvement and argument strength. Basic and Applied Social Psychology, 36(6), 461-477. doi:10.1080/01973533.2014.958226

Warner, L. A., Rumble, J., Martin, E., Lamm, A. J., \& Cantrell, R. (2015). The Effect of Strategic Message Selection on Residents' Intent to Conserve Water in the Landscape. Journal of Agricultural Education. 56(4). 59 - 74. doi:10.5032/jae.2015.04059 
Wasserstein, R. L., \& Lazar, N. A. (2016). The ASA's statement on p-values: Context, process, and purpose. The American Statistician, 70(2), 129-133. doi:10.1080/00031305.2016.1154108

Weatherell, C., Tregear, A., \& Allinson, J. (2003). In search of the concerned consumer: UK public perceptions of food, farming, and buying local. Journal of Rural Studies, 19(2), 233-244. doi:10.1016/S0743-0167(02)00083-9.

Weitkamp, E. (2016). Trust, advertising and science communication. Journal of Science Communication. 15(5). 1-4. https://doi.org/10.22323/2.15050501

Wilkins, K., Gorham, L., \& Meyers, C. (2017). Visualizing values: A content analysis to describe a value congruent video message campaign used in agriculture. Paper presented at the Southern Association of Agricultural Scientists: Agricultural Communications Section, Mobile, AL.

Woteki, C. (2012, February 23). Bridging the gap on agricultural research and development with the private sector. The United States Department of Agriculture. Retrieved from http://blogs.usda.gov/2012/02/23/bridging-the-gap-on-agricultural-research-anddevelopment-with-the-private-sector/

Wu, W. (2011). Confronting many-many problems: Attention and agentive control. Noûs, 45, 50-76. doi:10.1111/j.1468-0068.2010.00804.x

Zaichkowsky, J. L. (1994). The personal involvement inventory: Reduction, revision, and application to advertising. Journal of advertising, 23(4), 59-70. doi:10.1080/00913367.1943.10673459.

Zillman, D. \& Bryant, J. (1985). Selective Exposure to Communication. Hillsdale, New Jersey: Lawrence Erlbaum Associates. 